\title{
Optimization of Process Parameters in Turning Operation of AISI-1016 Alloy Steels with CBN Using Taguchi Method And Anova
}

\author{
K.Mani lavanya ${ }^{1}$, R.K.Suresh ${ }^{2}$,A.Sushil Kumar Priya ${ }^{3}$,V.Diwakar Reddy ${ }^{4}$. \\ ${ }^{1}$ PG Scholar, ${ }^{2}$ Asst. Professor (Sr), Department of Mechanical Engineering, Srikalahasteeswara Institute of \\ Technology, Srikalahasti. ${ }^{3}$ Department of Mechanical Engineering, Govt Polytechnic college, Gudur. \\ ${ }^{4}$ Department of Mechanical Engineering, S.V.U College of Engineering, S.V University, Tirupati.
}

\begin{abstract}
This paper investigates the parameters affecting the roughness of surfaces produced in the turning process for the material AISI-1016 Steel. Design of experiments was conducted for the analysis of the influence of the turning parameters such as cutting speed, feed rate and depth of cut on the surface roughness. The results of the machining experiments for AISI-1016 were used to characterize the main factors affecting surface roughness by the Analysis of Variance (ANOVA) method. The feed rate was found to be the most significant parameter influencing the surface roughness in the turning process.
\end{abstract}

Keywords - AISI-1016 steel, ANOVA, surface roughness, Taguchi method, turning.

\section{INTRODUCTION}

Today's modern machining industries face challenge to achieve high quality in terms of work piece dimensional accuracy, surface finish, less wear on cutting tools, economy of machining in terms of cost saving. Surface roughness of the machined part is the most important criteria to judge the quality of operation. The literature survey has revealed that several researchers have attempted to calculate the optimum cutting conditions in a turning operation. Brewer and Rueda developed various monograms to assist in the selection of optimum conditions [1]. Some of the other techniques which have been used to optimize the machining parameters include goal programming [2] and geometrical programming [3] Now a day's more attention is given to accuracy and surface roughness of the product in the industries. Surface roughness is the most important criteria in determining the machinability of the material.Surface roughness and dimensional accuracy are the major factors needed to predict the machining performances of any machining operation [4]. Optimization of machining parameters increases the utility for machining parameters increases the utility for machining economics and also increases the product quality to greater extent [5].

\section{TAGUCHI METHOD}

Taguchi's parametric design is the effective tool for robust design it offers a simple and systematic qualitative optimal design to a relatively low cost. The Taguchi method of off-line (Engineering) quality control encompasses all stages of product/process development. However the key element for achieving high quality at low cost is Design of Experiments (DOE). In this paper Taguchi's (DOE) approach is used to analyze the effect of process parameters like cutting speed, feed, and depth of cut on Surface Roughness of AISI-1016 work material while machining with CBN tool and to obtain an optimal setting of these parameters that may result in good surface finish.

\subsection{ANOVA (Analysis Of Variance)}

ANOVA can be useful for determining influence of any given input parameter from a series of experimental results by design of experiments for machining process and it can be used to interpret experimental data. Analysis of variance (ANOVA) is a collection of statistical models, and their associated procedures, in which the observed variance in a particular variable is partitioned into components attributable to different sources of variation. In its simplest form, ANOVA provides a statistical test of whether or not the means of several groups are all equal, and therefore generalizes $t$-test to more than two groups.

ANOVA is used in the analysis of comparative experiments, those in which only the difference in outcomes is of interest. The statistical significance of the experiment is determined by a ratio of two variances. This ratio is independent of several possible alterations to the experimental observations: Adding a constant to all observations does not alter significance. Multiplying all observations by a constant does not alter significance. So ANOVA statistical significance results are independent of constant bias and scaling errors as well as the units used in expressing observations. 


\section{Experimental Details}

The experiment was conducted using work piece material AISI-1016. The cutting tool used was Cubic Boron Nitrite. CBN is the second only to diamond in the hardness. The tests were carried for a length of $300 \mathrm{~mm}$ in a PSGA141 Conventional lathe. The cutting parameters are shown in the Table -1. Three levels of cutting speed, feed and depth of cut were used and are shown in the Table-1.

Table-1 Cutting parameters and levels

\begin{tabular}{|c|c|c|c|c|}
\hline \multirow{2}{*}{ Code } & \multirow{2}{*}{ Cutting parameter } & \multicolumn{3}{|c|}{ Levels } \\
\cline { 3 - 5 } & & 1 & 2 & 3 \\
\hline A & Speed's(rpm) & 360 & 740 & 1150 \\
\hline B & Feed,f(mm/rev) & 0.05 & 0.1 & 0.13 \\
\hline C & Depth of cut ,d(mm) & 0.5 & 0.75 & 1.0 \\
\hline
\end{tabular}

\subsection{Work-piece material and cutting tool insert.}

AISI-1016 steel is used as a work piece material for carrying out the experimentation to optimize the surface roughness. The bars used are of $50 \mathrm{~mm}$ diameter and $300 \mathrm{~mm}$ length. and its chemical composition is given in Table- 2 .

In these experiments, Cubic Boron Nitride inserts are used. Initially a rod of length $300 \mathrm{~mm}$ is taken and $50 \mathrm{~mm}$ length is placed inside the chuck of a lathe the remaining $250 \mathrm{~mm}$ is turned for each trial and divided in to 50 parts each $5 \mathrm{~mm}$ and then by using stylus (Surf test SJ210-P) instrument the surface roughness is measured between each part.

Table-2.Chemical composition of AISI-1016

\begin{tabular}{|c|c|c|}
\hline S.No & Metal & Range \\
\hline 1 & Carbon & $0.36-0.44 \%$ \\
\hline 2 & Silicon & $0.10-0.35 \%$ \\
\hline 3 & Manganese & $0.45-0.70 \%$ \\
\hline 4 & Sulphur & $0.040 \%$ \\
\hline 5 & phosphorous & $0.035 \%$ \\
\hline 6 & Chromium & $1.0-1.40 \%$ \\
\hline 7 & Molybdenum & $0.20-0.35 \%$ \\
\hline 8 & Nickel & $1.30-1.70 \%$ \\
\hline
\end{tabular}

Table-3.Mechanical properties of AISI-1016

\begin{tabular}{|c|c|c|}
\hline S.No & Mechanical property & Range \\
\hline 1 & max stress & $850-1000 \mathrm{~N} / \mathrm{mm}^{2}$ \\
\hline 2 & yield stress & $680 \mathrm{~N} / \mathrm{mm}^{2}$ \\
\hline 3 & Elongation & $13 \%$ \\
\hline 4 & Impact kcv & 15 joules \\
\hline 5 & Hardness & $248-302$ brinell \\
\hline
\end{tabular}

\section{Experimental Readings}

The surface roughness of machined surface has been measured by a stylus (Surf test SJ 210-P instrument) the dependent variable is surface roughness. The below table shows standard $L_{27}\left(3^{3}\right)$ Orthogonal Array designed by Taguchi with Experimental results. The left side of the below table includes coding values of control factors and real values of cutting parameters. The right side of the below table includes the results of the measured values of the surface roughness and calculated $\mathrm{S} / \mathrm{N}$ ratio. The different units used here are: speed $\mathrm{rpm}$, feed $-\mathrm{mm} / \mathrm{rev}$, depth of cut $-\mathrm{mm}$ and surface roughness $-\mathrm{Ra}-\mu \mathrm{mm}$. Designed - MINI TAB 16 software was used for Taguchi's Method and for analysis of variance (ANOVA).

\begin{tabular}{|c|c|c|c|c|c|c|c|c|}
\hline \multirow[t]{3}{*}{ Experiment No } & \multicolumn{3}{|c|}{ Control Factors } & \multicolumn{3}{|c|}{ Parameters } & \multirow{3}{*}{$\begin{array}{c}\text { Surface } \\
\text { Roughness } \\
\text { (Ra) } \mu \mathrm{mm}\end{array}$} & \multirow{3}{*}{$\begin{array}{c}\text { S/N } \\
\text { Ratio }\end{array}$} \\
\hline & $\mathbf{A}$ & B & $\mathrm{C}$ & \multirow{2}{*}{$\begin{array}{c}\text { Speeds } \\
\text { (rpm) }\end{array}$} & \multirow{2}{*}{$\begin{array}{l}\text { Feed (f) } \\
\mathrm{mm} / \mathrm{rev}\end{array}$} & \multirow{2}{*}{$\begin{array}{c}\text { DOC } \\
\text { (d) } \\
\mathbf{m m} \\
\end{array}$} & & \\
\hline & $\mathbf{s}$ & $\mathbf{f}$ & d & & & & & \\
\hline 1 & 1 & 1 & 1 & 360 & 0.05 & 0.5 & 1.84 & -5.9236 \\
\hline 2 & 1 & 1 & 2 & 360 & 0.05 & 0.75 & 2.01 & -6.0639 \\
\hline 3 & 1 & 1 & 3 & 360 & 0.05 & 1.0 & 1.78 & -5.0084 \\
\hline 4 & 1 & 2 & 1 & 360 & 0.1 & 0.5 & 2.18 & -6.7690 \\
\hline 5 & 1 & 2 & 2 & 360 & 0.1 & 0.75 & 1.92 & -5.666 \\
\hline 6 & 1 & 2 & 3 & 360 & 0.1 & 1.0 & 2.08 & -6.3612 \\
\hline 7 & 1 & 3 & 1 & 360 & 0.13 & 0.5 & 2.24 & -7.0049 \\
\hline
\end{tabular}


Optimization of Process Parameters in Turning Operation of AISI-1016 Alloy Steels with CBN

\begin{tabular}{|c|c|c|c|c|c|c|c|c|}
\hline 8 & 1 & 3 & 2 & 360 & 0.13 & 0.75 & 2.1 & -6.4443 \\
\hline 9 & 1 & 3 & 3 & 360 & 0.13 & 1.0 & 2.49 & -7.9239 \\
\hline 10 & 2 & 1 & 1 & 740 & 0.05 & 0.5 & 1.98 & -5.9333 \\
\hline 11 & 2 & 1 & 2 & 740 & 0.05 & 0.75 & 1.87 & -5.4368 \\
\hline 12 & 2 & 1 & 3 & 740 & 0.05 & 1.0 & 1.73 & -4.7609 \\
\hline 13 & 2 & 2 & 1 & 740 & 0.1 & 0.5 & 1.78 & -5.0084 \\
\hline 14 & 2 & 2 & 2 & 740 & 0.1 & 0.75 & 1.82 & -5.2014 \\
\hline 15 & 2 & 2 & 3 & 740 & 0.1 & 1.0 & 2.09 & -6.4029 \\
\hline 16 & 2 & 3 & 1 & 740 & 0.13 & 0.5 & 2.18 & -6.7691 \\
\hline 17 & 2 & 3 & 2 & 740 & 0.13 & 0.75 & 2.08 & -6.3612 \\
\hline 18 & 2 & 3 & 3 & 740 & 0.13 & 1.0 & 2.17 & -6.7291 \\
\hline 19 & 3 & 1 & 1 & 1150 & 0.05 & 0.5 & 1.72 & -4.7105 \\
\hline 20 & 3 & 1 & 2 & 1150 & 0.05 & 0.75 & 1.74 & -4.8109 \\
\hline 21 & 3 & 1 & 3 & 1150 & 0.05 & 1.0 & 1.76 & -4.9102 \\
\hline 22 & 3 & 2 & 1 & 1150 & 0.1 & 0.5 & 1.83 & -5.2490 \\
\hline 23 & 3 & 2 & 2 & 1150 & 0.1 & 0.75 & 1.94 & -5.7560 \\
\hline 24 & 3 & 2 & 3 & 1150 & 0.1 & 1.0 & 2.19 & -6.8088 \\
\hline 25 & 3 & 3 & 1 & 1150 & 0.13 & 0.5 & 2.49 & -7.9239 \\
\hline 26 & 3 & 3 & 2 & 1150 & 0.13 & 0.75 & 2.42 & -7.6763 \\
\hline 27 & 3 & 3 & 3 & 1150 & 0.13 & 1.0 & 2.24 & -7.0049 \\
\hline
\end{tabular}

Table-4.ANOVA readings for surface roughness

\begin{tabular}{|c|c|c|c|c|c|}
\hline Source & DOF & S.S & M.S & F value & C\% \\
\hline Speed(V) & $\underline{2}$ & 0.0516 & 0.0258 & 3.473 & 3.67 \\
\hline $\begin{array}{c}\text { Feed } \\
\text { Rate(f) }\end{array}$ & 2 & 0.9064 & 0.4532 & 61.020 & 64.5 \\
\hline $\begin{array}{c}\text { Depth Of } \\
\text { Cut(d) }\end{array}$ & 2 & 0.02272 & 0.01136 & 1.529 & 1.618 \\
\hline $\mathrm{V} * \mathrm{f}$ & 4 & 0.08356 & 0.02089 & 2.8127 & 5.95 \\
\hline $\mathrm{V} * \mathrm{~d}$ & 4 & 0.0033 & 0.000825 & 0.111 & 0.235 \\
\hline $\mathrm{F} * \mathrm{~d}$ & 4 & 0.2771 & 0.069275 & 9.3267 & 19.70 \\
\hline
\end{tabular}

DOF - Degrees of freedom, S.S - Sum of Squares, M.S - Mean of Squares and C - Contribution from the ANOVA Table-4 it is evident that the maximum contribution factor is feed having percentage contribution up to $64.5 \%$. After that second main contribution is speed having percentage contribution up to $3.67 \%$ and depth of cut has very little role to play on surface roughness. Hence the individual ranking of cutting parameters on the average value of mean on surface roughness are shown in Table- 5 .

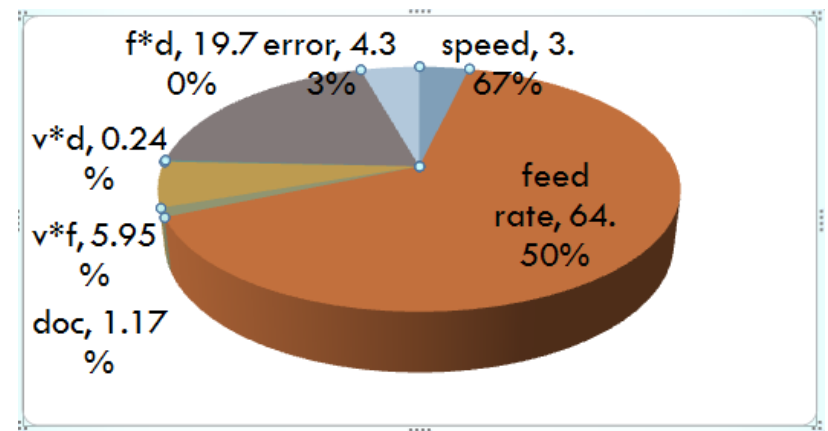

Table-5.Ranking of cutting parameters

\begin{tabular}{|c|c|c|c|}
\hline Level & Speed & Feed & Depth Of Cut \\
\hline 1 & 2.0711 & 1.837 & 2.026 \\
\hline 2 & 1.9666 & 1.981 & 1.9866 \\
\hline 3 & 2.0666 & 2.267 & 2.059 \\
\hline Rank & 2 & 1 & 3 \\
\hline
\end{tabular}

\section{Mathematical Modelling}

A Regression model was developed for surface roughness using Minitab-16 software. The predictions are speed, feed and depth of cut. Regression equation for surface roughness is

$\operatorname{Ra}(\mu \mathrm{m})=\mathrm{e}^{1.34} \mathrm{~S}^{0.0236} \mathrm{f}^{0.204} \mathrm{~d}^{0.0208}$ 


\section{MINI TAB RESULTS}

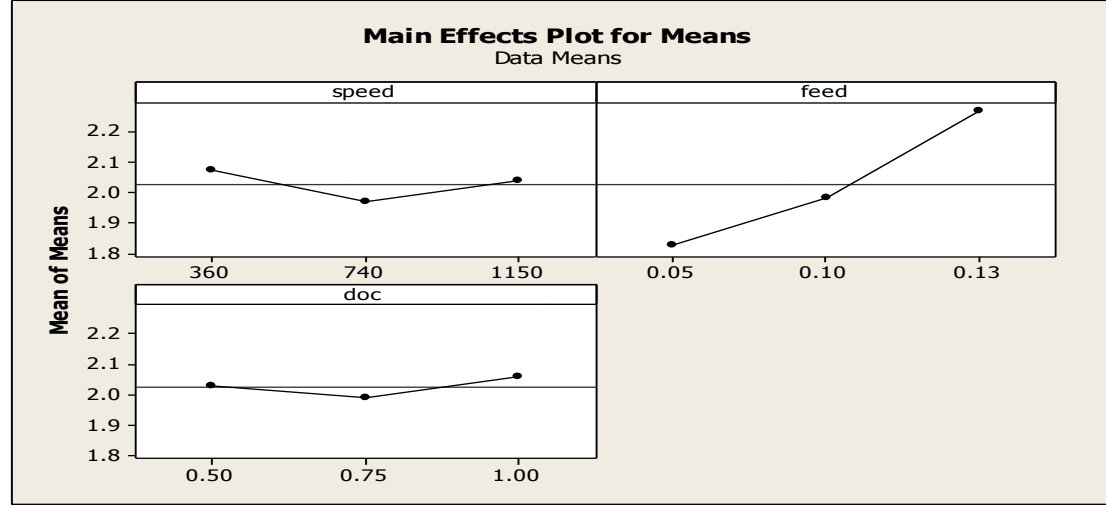

Effect of Turning Parameters on Surface Roughness

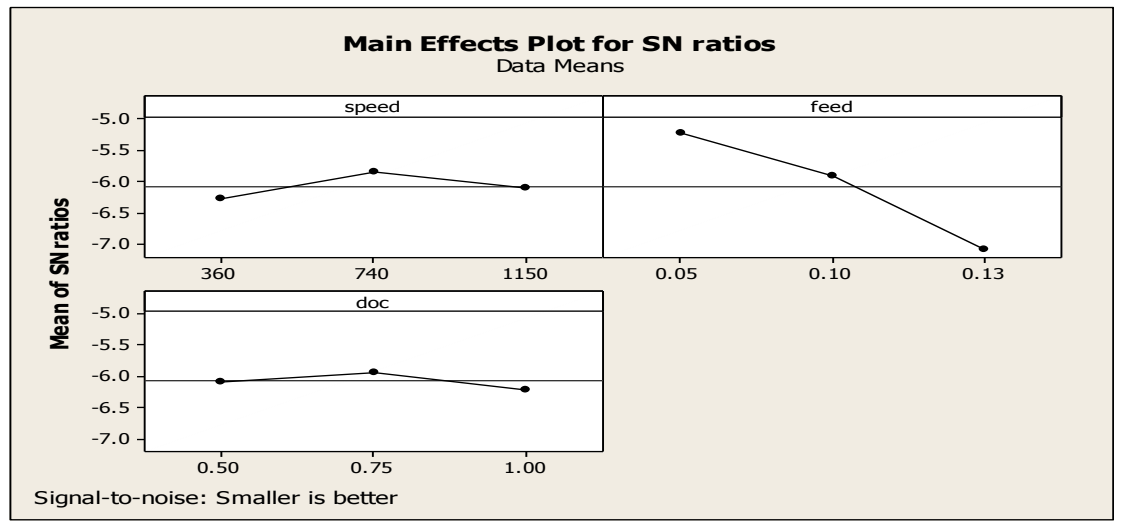

S/N Ratio values for Surface Roughness

\section{CONCLUSION}

Following are the conclusions drawn based on the test conducted on AISI 1016 alloy during turning operation with Cubic Boron Nitride.

1. From the results obtained a Regression Model has been developed for Surface Roughness. From this equations we can predict the value of Surface Roughness if the values of Cutting Speed, Feed and Depth of Cut are known.

2. From ANOVA Table and Response Table for Signal to noise ratios, based on the ranking it can be concluded that Speed has a greater influence on the Surface Roughness followed by Feed. Depth of Cut had least influence on Surface Roughness.

3. The validation experiment confirmed that the error occurred was less than that $2.0 \%$ between equation and actual value.

4. The optimal settings of process parameters for optimal Surafce Roughness are:

Speed(740), Feed (0.05) and DOC (1.0).This research gives us how Taguchi's parameter design to obtain optimum condition with lowest cost, minimum number of experiments and Industrial Engineers can use this method. The research can be extended for other materials using Tool Nose Radius, Lubricant Material Hardness etc as parameters.

\section{REFERENCES}

[1] E.J.A Armarego and R.H Brown, The machining of metals prentice Hall, 1969

[2] R.M Sundaram, “An application of Goal programming technique in metal cutting”,Int.J.Prod.Res.,vol.16,NO5,1978,PP375-382

[3] P.G.Petropoulos "optimum solution of machining rate variable by Geometric programming”, Int.J.Prod.Res ,vol.11,NO,4,1973.PP.305-314

[4] A.Mital, M.Mehta, "surface roughness Prediction models for fine turning", International journal of production research 26(1988) $1861-1867$

[5] R.Azouzi,M.Guillot, "on-line optimization of the turning using an inverse process neuro controller transalation" ASME, journal of manufacturing science and engineering 120 (feb)(1998)101-107. 